\title{
A PERSISTÊNCIA DO TRABALHO INFANTIL NO BRASIL E EM PORTUGAL E A QUESTÃO DA EDUCAÇÃO
}

\author{
THE PERSISTENCE OF CHILD LABOR IN BRAZIL AND PORTUGAL AND THE \\ EDUCATION
LA PERSISTENCIA DEL TRABAJO INFANTIL EN BRASIL Y EN PORTUGAL Y LA CUESTIÓN DE LA EDUCACIÓN

Soraya Franzoni Conde* sorayafconde@gmail.com

\author{
REVISTA PEDAGÓGICA \\ Revista do Programa de Pós-graduação em Educação da Unochapecó | ISSN 1984-1566 \\ Universidade Comunitária da Região de Chapecó | Chapecó-SC, Brasil \\ Revista Pedagógica, Chapecó, v. 19, n. 41, p. 168-193, maio./ago. DOI: http://dx.doi.org/10.22196/rp.v19i41.3797
} Como referenciar este artigo: CONDE, S. F. A persistência do trabalho infantil no Brasil e em Portugal e a questão da educação.

RESUMO: Este artigo aborda a persistência do problema do trabalho infantil em Brasil e em Portugal e a relação com a educação. Percorre as legislações existentes sobre a temática, as políticas e os dados estatísticos nos dois países. Com base em referencial teórico crítico, percebe que embora legislações, políticas sociais e educacionais tentem resolver o problema por meio da escolarização, a sua persistência indica os limites das reformas frente às contradições inerentes ao sistema capitalista.

Palavras-chave: Trabalho Infantil. Brasil. Portugal. Educação.

ABSTRACT: This article addresses the persistence of the problem of child labor in Brazil and Portugal and the relationship with education. It covers existing legislation on the subject, policies and statistical data in the two countries. On the basis of a critical theoretical framework, he realizes that although legislation, social and educational policies attempt to solve the problem through schooling, its persistence indicates the limits of the reforms to the contradictions inherent in the capitalist system.

Keywords: Child Labor. Brazil. Portugal. Education.

RESUMEN: Este artículo aborda la persistencia del problema del trabajo infantil en Brasil y en Portugal y la relación con la educación. Recorre las legislaciones existentes sobre la temática, las políticas y los datos estadísticos en los dos países. Con base en referencial teórico crítico, percibe que aunque legislaciones, políticas sociales y educativas intenten resolver el problema por medio de la escolarización, su persistencia indica los límites de las reformas frente a las contradicciones inherentes al sistema capitalista.

Palabras clave: Trabajo Infantil. Brasil. Portugal. Educación. 


\footnotetext{
* Doutora em Educação pela UFSC. Professora do Departamento de Estudos Especializados em Educação e do Programa de Pós Graduação em Educação da UFSC. É colaboradora do Programa de Pós Graduação em Serviço Social da mesma universidade. Vice líder do Núcleo de Estudos sobre as Transformações no Mundo do Trabalho (TMT/ CED/UFSC).
}

\section{INTRODUÇÃO}

\author{
"O trabalho de miúdo é pouco, mas \\ quem desperdiça é louco". \\ (provérbio português)
}

O provérbio popular acima, encontrado em publicações portuguesas sobre o trabalho infantil, é também conhecido no Brasil, aparecendo nas conversas informais realizadas com trabalhadores do campo e da cidade da seguinte forma: "Trabalho de criança é pouco, mas quem abre mão dele é louco". Essas semelhanças entre a exploração de adultos e de crianças no Brasil e em Portugal nos permitem perceber a generalidade da exploração humana, independentemente da idade, do sexo, da etnia, da nacionalidade.

Neste artigo, trataremos de um tópico da pesquisa referente às soluções para o trabalho infantil decorrentes da pesquisa realizada no Brasil e no doutorado-sanduíche em Portugal. Percorremos a literatura sobre o tema, as legislações vigentes, as políticas públicas, os dados estatísticos e realizamos visitas a exposições fotográficas e a museus com o objetivo de conhecer a problemática do objeto de estudo fora das fronteiras brasileiras. Percebemos que onde o capital vai seus problemas vão atrás (SILVER, 2005).

Não pretendemos realizar uma análise comparativa entre Brasil e Portugal no que se refere ao trabalho infantil, mas utilizarmos os exemplos portugueses e brasileiros para ilustrar a universalidade da relação capitalista e dos problemas a ela inerentes. As soluções propostas ao trabalho infantil em ambos os países visam a reformar o capitalismo, amenizando suas cruéis contradições. Assim, a legislação proíbe o trabalho de crianças, a escola torna-se obrigatória, e as políticas de transferência de renda "jorram água em cesto" (OLIVEIRA, 2003). Não obstante, a exploração do trabalho infantil persiste, como atestam os dados do Sistema de Informação Estatística sobre o Trabalho Infantil (SIET) e do Instituto Brasileiro de Geografia e Estatística (IBGE) apresentados no final deste texto.

\section{AS SOLUÇÕES AO PROBLEMA DO TRABALHO INFANTIL}

As soluções implementadas ao problema do trabalho no Brasil e em Portugal pautam-se em concepções reformistas do modo capitalista de produção. Conforme Ferraro (2009), o capitalismo e o liberalismo mantiveram uma relação conflituosa com a escola, tendo, em três autores expoentes, formas emblemáticas de pensar a educação: Mandeville (1670-1733), que se posicionava contra a intervenção do Estado na educação, pois o povo instruído não suportaria com satisfação seu ofício tendo a ignorância um papel estratégico na submissão; Adam Smith (1723-1790), que defendia o ensino privado e a intervenção estatal na 
educação do povo realizada em "doses homeopáticas"; Condorcet (1747-1794), que, com base no princípio de igualdade, defendia a instrução pública igual e para todos como meio de: igualdade de direitos, diminuição das desigualdades, aumento das ideias úteis, profissionalização, progresso e aperfeiçoamento da espécie humana.

Entre os liberais notáveis citados por Ferraro (2009), destacamos o escocês Adam Smith, fundador do liberalismo econômico, pela semelhança entre suas defesas e as propostas educacionais atuais para o campo e para a cidade no Brasil. Já no século XVIII, Smith (1989) observou que a especialização do trabalho individual, ao mesmo tempo em que gerava o aumento da produtividade do trabalho, condenava os trabalhadores a tarefas muito simples, comprometendo o seu desenvolvimento intelectual:

O homem que passa toda a sua vida a executar algumas operações simples, cujos efeitos são sempre os mesmos, ou quase, não tem ocasião de exercitar a sua capacidade intelectual ou a sua habilidade de encontrar expedientes para afastar as dificuldades que nunca ocorrem. Perde naturalmente, portanto, o hábito desse exercício e torna-se geralmente tão estúpido e ignorante quanto é possível conceber-se numa criatura humana. $\mathrm{O}$ torpor do seu raciocínio torna-se não só incapaz de saborear ou tomar parte de qualquer conversa racional como também de conceber qualquer sentimento generoso, nobre ou terno, e, por consequência, até incapaz de formar qualquer julgamento sensato no que diz respeito a muitos dos deveres da vida privada. Dos grandes e mais vastos interesses do seu país é completamente incapaz de julgar; e a menos que haja um esforço muito particular para o modificar, é igualmente incapaz de defender o seu país numa guerra. [...] A destreza que possui no seu ofício particular parece, deste modo, ser adquirida à custa das suas virtudes intelectuais, sociais e marciais. (SMITH, 1989, p. 416-417).

Smith (1989) reconhecia os problemas ocasionados pelo trabalho repetitivo na indústria capitalista emergente em sua época e defendia o ensino privado, pago com as capacidades produzidas do trabalho de cada indivíduo. Mesmo assim, o Estado se responsabilizaria pela educação da gente comum, de acordo com os interesses de uma sociedade comercial. Seria um ensino em "doses homeopáticas" voltado à aprendizagem básica exigida pelo modo de vida urbano e industrial: ler, escrever e contar.

Para o autor, a desigualdade social era produto do trabalho, mas sua origem estava atrelada às políticas que não permitiam liberdade plena às coisas. Assim, Smith (1989) defendia um sistema social fundamentado na liberdade natural e na livre concorrência, na não intervenção do Estado na economia e na atuação do Estado na esfera da defesa, da 
justiça e dos serviços públicos institucionais, por exemplo, a educação escolar do povo comum, para uma aprendizagem elementar, conforme ilustramos anteriormente.

Conforme Mészáros (2005), a educação é uma peça-chave do processo de expansão do capital tanto para a qualificação ao trabalho industrial quanto para a transmissão dos valores de manutenção de sua ordem. Segundo o autor, para pensar a educação é preciso pensar onde está o trabalho. Nesse sentido, qualquer reforma educacional somente tem sentido com a reformulação das práticas existentes e, caso essa relação seja negada, ocorrerão apenas ajustes menores com reformas que remedeiem os seus piores efeitos. Mas Mészáros (2005) adverte que o capital é um todo estruturado, e seus defeitos específicos não podem ser modificados superficialmente sem uma referência ao modo geral de funcionamento. Ou o sistema se impõe com êxito sobre o todo ou perde sua viabilidade como regulador dominante da reprodução metabólica universal. Limitar a mudança às margens educacionais significa abandonar uma transformação social qualitativa, como fazem as políticas públicas liberais direcionadas, por exemplo, à qualificação profissional para o combate ao desemprego e o encaminhamento das crianças trabalhadoras para a escola, como se fossem as ausências de qualificação profissional e de escolarização as responsáveis por esses problemas.

Se a educação não é a força ideologicamente primária que consolida o sistema do capital, tanto menos ela é capaz de fornecer uma alternativa emancipadora radical. Ela produz conformidade e consenso dentro de seus limites legais e institucionais. Por isso, seus debates, ao menos, precisam abarcar questões críticas essenciais, defende Mészáros (2005). Embora diante desses limites em relação às questões totalitárias que envolvem a transformação social, o autor reconhece que a escolarização da classe trabalhadora é uma questão dialética, de importância destacada, pois não há nenhuma ação humana sem intervenção intelectual. A educação escolar é um instrumento que potencializa o trabalhador na luta contra sua exploração.

No mesmo sentido das reformas pontuais liberais descoladas da ordem totalitária do sistema, no âmbito das ações políticas internacionais são desenvolvidas legislações e metas para a erradicação do trabalho infantil no mundo. Após o final da Primeira Guerra Mundial, em 1919, criou-se a Organização Internacional do Trabalho (OIT) e, em 1939, o Fundo das Nações Unidas para a Infância (Unicef) para tratar das políticas relacionadas à infância nos países pobres. A criação da OIT e do Unicef foi realizada no sentido de separar decisões financeiras internacionais das metas que agem sobre os efeitos dos problemas criados pelo sistema capitalista de produção. As decisões econômicas e os rumos do capitalismo internacional permanecem sob o controle do Banco Mundial (BM) e da Organização Mundial do Comércio (OMC). Por isso, os movimentos sociais passam a denunciar a inviabilidade material, dentro dos 
limites do capital, das legislações promulgadas pela OIT e pelo Unicef, impostas e definidas pelos organismos financeiros internacionais.

As principais soluções e metas apontadas pela OIT e pelo Unicef para implementação nos países signatários estão na legislação proibitiva ao trabalho infantil e nas políticas públicas que combinam programas de transferência de renda e de ampliação do acesso à escolarização.

\section{A LEGISLAÇÃO BRASILEIRA}

A legislação brasileira é considerada uma das mais avançadas no mundo sobre o trabalho infantil, regulamentando-o na Constituição Federal, na Consolidação das Leis Trabalhistas (CLT) e no Estatuto da Criança e do Adolescente (ECA).

A primeira legislação data da Velha República. Segundo Aguiar (2004), Pilotti e Rizzini (1995), os primeiros indícios de resolução legal desse problema datam de 1891, quando foi aprovado o Decreto $\mathrm{n}^{\circ} 1.313$, que instituiu a fiscalização de todos os estabelecimentos industriais da capital federal e definiu a idade mínima para o início no trabalho: 12 anos. A legislação também definia que, de oito a 12 anos, permitia-se o trabalho na condição de aprendiz, desde que não colocasse em risco a vida dos pequenos trabalhadores. Em 1919, após o findar da Primeira Guerra Mundial, foi fundada a OIT, e o Brasil ratificou várias convenções, entre as quais, destacamos a convenção 05/1919 - idade mínima de 14 anos para o trabalho na indústria; e a convenção 6/1919 - proibiu o trabalho noturno de menores na indústria. No ano de 1927, como decorrência de pressões políticas internacionais, foi formulado o Código dos Menores, que limitou em seis horas o trabalho diário, com uma hora para repouso, e proibiu as atividades insalubres para menores de 18 anos. A primeira Consolidação das Leis Trabalhistas (CLT), formulada em 1943, redefiniu a idade mínima para 14 anos e, no ano de 1988, a Constituição Federal manteve essa idade.

O Estatuto da Criança e do Adolescente (ECA), formulado no Brasil em 1990, permite o trabalho infantil aprendiz entre 14 e 16 anos. No ano de 1998, a Emenda Constitucional $\mathrm{n}^{0} 20$ alterou a idade mínima para 16 anos e permitiu o trabalho aprendiz entre 14 e 16 anos. Em seguida, foram ratificadas as convenções da OIT $\left(n^{0} 138\right.$, idade mínima para o trabalho, e $\mathrm{n}^{0} 182$, piores formas de trabalho infantil), e vários programas de governos e ações de entidades não governamentais foram efetuados (BRASIL, 1999, 2002).

Uma das questões legislativas polêmicas relativas ao trabalho infantil na atualidade diz respeito à permissão do trabalho entre 14 e 16 anos na condição de aprendiz e à definição das "piores formas" de trabalho infantil. 
A permissividade legal da contratação do aprendiz e os incentivos fiscais ao contratante tornam o emprego de adolescentes mais vantajoso do que o de adultos para muitas tarefas cujo desenvolvimento não ultrapassa os limites de trabalho simples.

$\mathrm{Na}$ atualidade, encontram-se em discussão as Propostas de Emendas Constitucionais que almejam reduzir a idade mínima do trabalho aprendiz no Brasil de 14 anos para 12 anos. As PECs contradizem a convenção $\mathrm{n}^{0} 18 \mathrm{da}$ OIT, da qual o Brasil é signatário, em que a idade mínima para o trabalho não pode ser inferior ao término da escolaridade obrigatória (18 anos, no caso brasileiro, quando se costuma concluir o Ensino Médio). Dessa forma, observamos, por meio dos embates legais em torno do problema do trabalho infantil no Brasil, a perpetuação de conflituosos debates entre os defensores liberais da escolaridade mínima e a universalização da educação pública capaz de permitir o acesso ao conhecimento historicamente acumulado pela humanidade.

A proposta de diminuição da idade mínima para o trabalho representa uma tentativa de avanço das forças mais conservadoras do liberalismo nacional que visam a diminuir, tanto quanto possível, a instrução pública estatal desses adolescentes, inserindo-os logo no trabalho produtivo, algo altamente vantajoso aos contratantes, além de concorrente desleal do desemprego adulto, tendo em vista o salário e os incentivos fiscais. A PEC em discussão tem como pressuposto que a educação desses adolescentes será voltada para as práticas efetivas de trabalho e de suas necessidades reais. Por isso, é importante garantir que frequentem a Educação Básica, assim como Adam Smith (1989) já admitia no século XVIII, preparando-os para uma maturidade capaz de suportar a jornada de trabalho.

Para Klein (2010), a questão legal do trabalho infantil é complexa e tangencia o problema contraditório do trabalho na sociedade capitalista, na qual ocorrem modos inaceitáveis de intensificação da jornada que prejudicam o desenvolvimento da criança e do adolescente e os modos de trabalho considerados necessários para a formação do ser humano. Essas contradições, para a autora, intrínsecas ao trabalho, são expressas na legislação que proíbe o trabalho insalubre, mas o permite na condição de aprendiz. Dessa forma, ignora-se o debate acerca da dimensão alienadora, explorada e degeneradora do trabalho submetido à lógica do capital, e o problema do trabalho infantil aparece associado às condições insalubres e à maldade dos empregadores. Abandonada a questão do trabalho produtor de mais-valia, resta definir formas de regulamentá-lo por idade e condições de trabalho.

\section{A LEGISLAÇÃO PORTUGUESA}

Enquanto no Brasil a primeira legislação que regulamenta o trabalho de crianças data de 1891, a primeira 
ação portuguesa nesse sentido data de 27 de julho de 1991. Portanto, antes dessa data, o trabalho de crianças não era considerado problema em Portugal. Em 1991, a legislação passou a incumbir o Estado da responsabilidade de promover um equilibrado desenvolvimento físico, mental e moral das crianças, salvaguardando-lhes a segurança e a saúde, garantindo escola, profissão e seguridade social. O Decreto-Lei $\mathrm{n}^{0} 3 \cdot 96 / 91$, de 16 de outubro, regulamenta o contrato individual de trabalho e introduz a idade mínima de 16 anos para admissão no trabalho, desde que o adolescente contratado tenha concluído a escolaridade obrigatória, conforme as orientações da OIT. No entanto, o mesmo Decreto admite exceções que se assemelham ao trabalho na condição de aprendiz no Brasil: quando frequentar o ensino profissionalizante e o trabalho não interferir no horário da escola, e desde que exista autorização dos pais; quando as atividades forem consideradas leves sem esforços físicos, sem riscos à saúde e ao desenvolvimento, com tarefas simples que exigem conhecimentos elementares. Assim como no Brasil, ao permitir exceções, a legislação portuguesa tende a combater as "piores" formas de trabalho infantil, e não a exploração do trabalho. Ou seja, não se trata de erradicar o pressuposto da acumulação capitalista, mas de criar condições para que essa forma social se reproduza, conferindo ao Estado, nos marcos do liberalismo, algumas responsabilidades acerca da educação dos filhos da classe trabalhadora.

\section{POLÍTICASDETRANSFERÊNCIADERENDA E DE AMPLIAÇÃO DA ESCOLARIZAÇÃO NO BRASIL E EM PORTUGAL}

Desde 1996, o governo federal brasileiro desenvolve programas de transferência de renda com o objetivo de solucionar os principais problemas sociais do País, entre os quais se destaca o trabalho infantil.

O Programa de Erradicação do Trabalho Infantil (PETI) foi criado como parte das políticas desenvolvidas no âmbito dos países signatários da OIT para atender crianças de cinco a 15 anos, por meio da concessão de uma bolsa para as residentes das áreas rurais e urbanas. Para receberem a bolsa, as crianças necessitam frequentar a escola, e as assistentes sociais do programa acompanham a frequência.

Kassouf e Ferro (2004), ao analisarem a eficácia desse programa, percebem que as crianças atendidas pelo PETI não deixam de trabalhar, mas diminuem, em duas ou três horas, a jornada semanal de trabalho, visto que passam a frequentar a escola em um período e a trabalhar no outro. Assim, as crianças que somente trabalhavam passam a estudar, e as que já estudavam complementam a renda familiar. Embora as crianças estejam na escola em virtude de o recebimento da bolsa depender da frequência escolar, como não é exigido que elas deixem de trabalhar, o programa acaba não atingindo o objetivo de solucionar o problema 
1 Sindicato da Indústria do Fumo da Região Sul do Brasil.

2 Associação dos Fumicultores do Brasil. do trabalho infantil. A erradicação, a que o programa se propõe, é delegada ao futuro e à possibilidade de quebra do ciclo da pobreza por meio da qualificação escolar.

Pincelli (2005) analisa o Programa "O futuro é agora”, desenvolvido desde 1998 pelo Sindifumo e pela Afubra $^{2}$, como decorrência do "Pacto do Setor Fumageiro pela Prevenção e Erradicação do Trabalho infantil na Produção de Fumo". Conforme a análise que a autora realizou das aulas e do material didático fornecidos pela empresa, o ensino é voltado ao trabalho do agricultor, à sua instrumentalização técnica e à aquisição de conhecimentos gerais, o que é altamente favorável à manutenção das formas integradas de trabalho na fumicultura. As novas técnicas de plantio exigem que o agricultor tenha maior escolarização para que, por exemplo, possa estar conectado à internet para receber orientações da empresa e, assim, reduzir os custos de viagens dos instrutores. Dessa forma, o programa aproveita o espaço escolar para qualificar o agricultor do futuro, conforme os interesses da empresa integradora.

Pincelli (2005) ressalta que, com o slogan da responsabilidade social, empresas como a Souza Cruz garantem competitividade e vendem uma imagem de "empresa amiga da criança" com produtos diferenciados nacional e internacionalmente. No fundo, o programa desenvolvido funciona como marketing empresarial, pois o consumidor europeu (principal mercado do fumo brasileiro) prefere produtos com uma imagem responsável. Além disso, a empresa recebe incentivos fiscais para o desenvolvimento do programa, o que evidencia que, no fundo, o Estado brasileiro é quem financia a formação voltada aos interesses comerciais da iniciativa privada, confirmando a importância da tríade Estado, capital e trabalho para a manutenção das estruturas sociais vigentes. Essa constatação, mais uma vez, evidencia a atualidade das propostas liberais de educação, que desde o século XVIII defendem a instrumentalização técnica dos filhos dos trabalhadores com a aprendizagem de conhecimentos gerais (na época: saber ler, escrever e contar).

Conforme Mészáros (2001, p. 121), as políticas públicas não estão acima da esfera produtiva, pois o Estado é parte intrínseca do capital:

O Estado moderno pertence à materialidade do sistema do capital e corporifica a necessária dimensão coesiva de seu imperativo orientado para a expansão do trabalho excedente. É isso o que caracteriza todas as formas conhecidas do Estado que se articula na estrutura da ordem sócio-metabólica [sic] do capital. Precisamente porque as unidades econômicas reprodutivas do sistema têm um caráter incorrigivelmente centrífugo - caráter que há longo tempo na história tem sido parte integrante do incomparável dinamismo do capital, ainda que em certo estágio de desenvolvimento ele se torne extremamente problemático e potencialmente destrutivo, a 
dimensão coesiva de todo sócio-metabolismo [sic] deve ser constituída como uma estrutura separada de todo metabolismo [...]. Entretanto, o princípio estruturador do Estado moderno em todas as formas - inclusive as variedades pós-capitalistas - é o seu papel vital de garantir e proteger as condições gerais de extração da mais-valia do trabalho excedente.

Seguindo a mesma perspectiva, Oliveira (2003) afirma que o papel do Estado é institucionalizar o jogo social, fixando regras e meios para a redistribuição de recursos entre classes capitalistas. Dentro das contradições inerentes à lógica que sustenta a acumulação de capital, cresce o trabalho infantil, e aumenta o número de ambulantes e de subempregados erroneamente chamados de informais. Esses trabalhadores compõem o trabalho abstrato virtual, argumenta o autor. As "[...] políticas piedosas tentam treinar e qualificar essa mão de obra, em um trabalho de Sísifo, jogando água em cesto, acreditando que o velho e o bom trabalho com carteira voltará" (OLIVEIRA, 2003, p. 143).

\section{A SOLUÇÃo PELA ESCOLA INTEGRAL NO BRASIL}

Desde 2008, as primeiras escolas brasileiras começaram a oferecer educação integral com jornada ampliada. Já em 2010, o Decreto $n^{0} 7.083$, buscando articular políticas voltadas à implementação de educação integral no Brasil, dispõe sobre o "Programa Mais Educação", cuja finalidade é contribuir na melhoria da aprendizagem e permanência de alunos matriculados em escolas públicas de educação integral. O programa visa à formulação de uma política nacional de Educação Básica integral que promova o diálogo entre diferentes culturas e saberes locais com a escola, favorecendo a convivência de professores, alunos e comunidade (BRASIL, 2010).

O mesmo decreto institui os princípios da Educação Integral Brasileira, afirmando que a constituição de territórios educativos integram espaço escolar e comunidade, refletindo a perspectiva da "cidade educadora", e esta conjuga a escola com diversos espaços socioculturais e esportivos. Durante a jornada ampliada, os estudantes frequentam aulas curriculares obrigatórias na escola, mas também buscam uma formação centrada no ser humano completo, na vida coletiva e na tolerância, em espaços localizados fora da escola (parques, praças, museus, bibliotecas, cinemas, teatros). O bairro, a cidade e o território são vistos como espaços potenciais de serem transformados em educativos. Com isso, o MEC espera conseguir aumentar o número de matrículas das escolas públicas, atendendo à necessidade de famílias trabalhadoras, retirando as crianças das ruas e do trabalho, diminuindo a evasão escolar com maior aproveitamento dos conteúdos e estímulo à participação coletiva e política no território. 
Segundo Moll (2008), a partir das demandas da Lei $\mathrm{n}^{\circ}$ 9.394, de 20 de dezembro de 1996 - Lei de Diretrizes e Bases da Educação Nacional (LDB) - que preconizam a ampliação da escola integral, é necessário que a sociedade se aproprie desse espaço, colocando o desenvolvimento humano como finalidade posta, combinando tempo integral com formação integral. A autora considera a formação de profissionais para essa finalidade um grande desafio, fato esse que corroboramos diante de tendências voluntárias, locais, não profissionais e espontâneas recorrentes em algumas experiências para o desenvolvimento das atividades esportistas, culturais, políticas e artísticas da jornada ampliada das escolas integrais. Conforme as informações coletadas na página do $\mathrm{MEC}^{3}$ e na pesquisa de Coelho (2004), as atividades complementares ao currículo obrigatório variam de cidade e região e são ministradas por estudantes, estagiários, graduandos, voluntários e professores, correndo o risco da não profissionalização e da indefinição prévia de quais aspectos estéticos, políticos, esportivos e coletivos são importantes na formação humana da escola integral. Ao não ter uma política clara, o MEC abre a possibilidade de tudo ser considerado complementar à formação integral, podendo ser desenvolvido por não profissionais da educação.

A expressão "cidade educadora" decorre também das tendências educacionais estimuladas pelo Unicef. Goulart (2008) faz referência à expressão "cidades educadoras" na Declaração de Barcelona, publicada em 1994 como decorrência do I Congresso de Cidades Educadoras. Portanto, a origem do termo é anterior à LDB/96. A Carta da Cidade Educadora (1994) prevê que as cidades se tornem espaços educativos e culturais, tendo em vista a formação do indivíduo e o desafio do século XXI:

O grande desafio do século XXI é investir na educação de cada indivíduo, de maneira que este seja cada vez mais capaz de exprimir, afirmar e desenvolver o seu próprio potencial humano. Potencial feito de individualidade, construtividade, criatividade e sentido de responsabilidade, assim como de um sentido de comunidade - capacidade de diálogo, de confrontação e de solidariedade. Uma cidade será educadora se oferecer todo o seu potencial de forma generosa, deixando-se envolver por todos os seus habitantes e ensinando-os a envolverem-se nela [...]. Com efeito, a cidade dispõe de um extenso leque de iniciativas educadoras, de origem, intenção e responsabilidades diversas. Ela dispõe de instituições de educação formal, de meios de intervenção não formais com objectivos [sic] pedagógicos preestabelecidos, assim como propostas ou experiências que surgem de uma forma aleatória ou nascem de critérios comerciais. E ainda que o conjunto das propostas apresente, algumas vezes, contradições ou evidencie desigualdades já existentes, elas encorajarão 
sempre a aprendizagem permanente de novas linguagens, oferecerão oportunidades de conhecer o mundo, permitirão o enriquecimento individual e a partilha de forma solidária. As cidades educadoras irão desenvolver uma colaboração bilateral ou multilateral para a troca das suas experiências; num espírito de cooperação apoiar-se-ão mutuamente no que respeitar a projectos [sic] de estudo e de investimento, quer directamente [sic], quer como intermediários em organismos internacionais. Por seu lado, as crianças e os jovens deixarão de ser protagonistas passivos da vida social e, por conseguinte, da cidade. [...] a proteção das crianças e dos jovens na cidade já não consiste só em privilegiar a sua condição mas também em encontrar o lugar que verdadeiramente os coloca ao lado dos adultos, considerando-se uma virtude de cidadania a satisfação mútua que deve presidir à coexistência entre gerações. (DECLARAÇÃO DE BARCELONA, 1990, p. 1).

Como podemos perceber, o documento é claro ao evidenciar que os princípios da cidade educadora estão na formação construtiva, criativa, solidária do indivíduo para a vida da cidade generosa, envolvente e acolhedora, que dispõe de meios formais de educação, mas também de formas aleatórias que nascem de critérios comerciais. Mesmo que ocorram as desigualdades, as cidades educadoras encorajam novas linguagens e o enriquecimento solidário individual com respeito às diferenças.

Em perspectiva oposta à cidade educadora, o pesquisador estadunidense Mike Davis (2006) publicou o livro Planeta favela e denunciou a produção em massa de favelas nas grandes cidades do planeta, alegando que "[...] 90\% do crescimento das famílias urbanas ocorreu nas favelas" (DAVIS, 2006, p. 28). A especulação imobiliária, o embelezamento e a elitização dos espaços urbanos expulsam milhões de moradores pobres das cidades para as sombras das periferias, onde prevalecem as moradias ilegais e irregulares em áreas precárias de deslizamento, de contaminação, de poluição, de alagamento e sem serviços públicos básicos, tais como abastecimento de água, energia elétrica, coleta de lixo e rede de esgoto. Acabou a terra gratuita ou barata nos arredores de grandes cidades ou em áreas de divisa. Dessa forma, ao invés de cidades educadoras, o século XXI apresenta cidades cercadas de poluição, excrementos, ruínas, violência e miséria. Nas palavras do autor:

Assim, as cidades do futuro, em vez de feitas de vidro e aço, como fora previsto por gerações anteriores de urbanistas, serão construídas em grande parte de tijolo aparente, palha, plástico reciclado, blocos de cimento e restos de madeira. Em vez de cidades de luz arrojando-se aos céus, boa parte do mundo urbano do século XXI instala-se na miséria, cercada 
de poluição, excrementos e deterioração. $\mathrm{Na}$ verdade, o bilhão de habitantes urbanos que moram nas favelas pós-modernas podem mesmo olhar com inveja as ruínas das robustas casas de barro de ÇatalHüyük, na Anatólia, construídas no arvorecer da vida urbana há 9 mil anos. (DAVIS, 2006, p. 29).

A população que habita as favelas, no caso brasileiro, é, em grande parte, oriunda dos descendentes de escravos, destinados a habitarem os locais de difícil acesso nos quais a burguesia não tinha interesse após a abolição da escravidão, e de trabalhadores rurais que migraram aos grandes centros urbanos em busca de trabalho e permanecem desempregados ou subempregados. As crianças e os adolescentes, filhas e filhos desses trabalhadores, perambulam e brincam nesses locais em meio ao lixo e à sujeira. Diante da necessidade urgente de lutarem pela sobrevivência e sem talentos urbanos (nas línguas, na Matemática e na informática), aumentam a lista de fracasso escolar por abandono e repetência. Entre esses, há os que começam a trabalhar desde cedo para as gangues de rua e o narcotráfico, e manipulam armamentos pesados, estando em constantes combates com policiais e traficantes, sob o risco iminente de morte. Nesse sentido, a proposta da cidade educadora esbarra nos limites dos territórios sujos, violentos, precários e poluídos das periferias e favelas dos grandes centros urbanos brasileiros.

Conforme Goulart (2008), durante muito tempo o debate sobre a escola integral foi deixado de lado no Brasil, porque se entendia que seria necessário dobrar a estrutura escolar para o atendimento. Mas agora, com a cidade educadora, é possível ampliar o tempo e o espaço escolar com custos reduzidos aproveitando o que os territórios possuem.

Para Maricato (2006), a defesa do território, do bairro e do local é uma armadilha que visa a esconder a política econômica internacional que determina grande parte dos problemas vividos nos locais periféricos. Esse localismo contradiz as formas como as políticas locais são determinadas globalmente. As taxas de juros do Brasil, por exemplo, são definidas pelo Banco Central, cujo presidente não foi eleito. Suas reuniões secretas com atas indecifráveis são orientadas pelo FMI que, por sua vez, defende a independência do Banco Central em relação ao Estado brasileiro.

Assim, percebemos que a proposta de educação integral ganha fôlego novamente no Brasil não somente para atender às demandas das famílias trabalhadoras, que necessitam de um local seguro para os filhos ficarem ou para eliminar o trabalho, ou ainda, para combater os velhos problemas educacionais (evasão e repetência), mas para alavancar iniciativas liberais de educação do indivíduo, tendo por princípio educar o cidadão pobre, com parcos recursos, nos limites das desigualdades do capitalismo. Os problemas decorrentes das desigualdades chegam à escola, mas 
ela pode ajustar e integrar o aluno à vida política e coletiva da cidade ou do território, distante das discussões econômicas que determinam grande parte dos problemas das famílias trabalhadoras que necessitam de escolas públicas de tempo integral para deixarem seus filhos enquanto trabalham.

Nessa mesma direção, Florestan Fernandes (1966) compreende que a educação, embora não dê conta de desencadear o progresso nem de provocar mudanças no curso da história - tal como pretendiam os teóricos iluministas da revolução francesa -, é um fator essencial para a classe trabalhadora caminhar rumo à mudança. Para o autor, qualquer que seja o grau de estabilidade social, a escola sempre está articulada aos processos de inovação. Ou, ainda, dependendo do grau de instabilidade, ela pode contribuir para a preservação da herança social e cultural. Assim, o autor acredita que a escola pode intervir positivamente no sistema por meio de projetos capazes de contribuir para as mudanças sociais provocadas.

Fernandes afirma, ainda: "Se é a educação que modela o homem, é ele, por sua vez, quem define a educação" (1966, p. 44). A boa educação, de acordo com o autor, continua sendo um privilégio tal qual era na sociedade escravocrata e senhorial. Inverter a lógica da expansão quantitativa da educação e defender uma escola pública, com objetivos, métodos, didáticas e conteúdos definidos dentro das novas tendências impostas pelos avanços científicos e tecnológicos é algo revolucionário para a ampliação do intelecto da classe trabalhadora do campo ou da cidade.

Na mesma perspectiva, Cunha (1991) também defende a escola para a classe trabalhadora. $\mathrm{O}$ autor ressalta que perceber a dialética da escola para a classe trabalhadora é diferente da crença na educação escolar como meio eficaz de constituição de uma sociedade aberta às potencialidades individuais. Essa ideologia individualista e liberal democrata esconde o lado sombrio do desenvolvimento econômico e de suas repercussões sociais, responsabilizando o indivíduo pelo próprio sucesso e justificando com normalidade a existência das classes sociais. Cunha (1991), ao analisar as origens do pensamento pedagógico, percebe as influências liberais na educação nacional. $\mathrm{O}$ autor percorre vários autores e identifica em John Dewey (1859-1952) grande influência no Brasil, principalmente por meio do pensamento de Anísio Teixeira (1900-1971), precursor da implantação das escolas integrais no País, no modelo Parque Escola.

Cunha (1991) argumenta que, ao contrário dos pressupostos liberais, as oportunidades de escolarização não são franqueadas a todos, uma vez que o sistema educacional é extremamente desigual em diferentes regiões e classes sociais do País. Mesmo onde há atendimento, a qualidade é desigual. Além disso, as aptidões das pessoas não são inatas, como induz o individualismo, mas produto de relações e da educação recebida no início da vida escolar. 
Mesmo diante da compreensão das complexas origens econômicas dos problemas educacionais da classe trabalhadora, Cunha (1991) não se prende às análises reprodutivistas e reconhece a importância da instituição escolar na formação da classe trabalhadora:

A escola não apenas inculca a ideologia dominante (da classe dominante) nos estudantes oriundos da classe trabalhadora, mas também e contraditoriamente, traz ganhos reais para estes. Aprender a ler, a escrever e a calcular, conhecer geografia, história e ciências não trazem para os estudantes apenas a ideologia dominante, mas permitem a eles, também, adquirir noções mais coerentes sobre a realidade do que permitiria, espontaneamente, a cultura da classe trabalhadora. (CUNHA, 1991, p. 7).

\section{POLÍtICAS DE TRANSFERÊNCIA DE RENDA E ESCOLA INTEGRAL EM PORTUGAL}

De acordo com as deliberações dos países signatários da OIT, Portugal, em 1998, definiu um Plano para a Eliminação da Exploração do Trabalho (Peeti) pela Resolução do Conselho de Ministros $n^{0} 75 / 98$. Seu objetivo principal é eliminar no país todas as formas do trabalho infantil. Após o recebimento da denúncia, as equipes multidisciplinares do Peeti analisam e caracterizam as situações encontradas por meio de fichas de dados e tipologia do trabalho. Em seguida, é realizada uma avaliação diagnóstica, sociofamiliar e escolar para preparar uma intervenção do programa governamental no problema familiar (SIET, 2008).

O exemplo do Peeti de Portugal, em termos de diagnóstico e intervenção, tem sido utilizado pela OIT em outros países europeus, pois, conforme relato de Paulo Bárcia (2008), diretor do Escritório da OIT em Lisboa, os países ricos europeus também têm problemas relacionados ao trabalho infantil, seja nos âmbitos domésticos, seja nos âmbitos familiares, artísticos, estejam as crianças frequentando as escolas ou não.

Outra política de enfrentamento do trabalho infantil em Portugal é o (Plano Integrado de Educação e Formação (PIEF), cujo principal objetivo é atuar no abandono escolar precoce por meio de projetos de educação para as crianças que não queiram voltar ao sistema educativo (PEETI, 2008a). O plano é orientado pela perspectiva de que é necessário preparar as crianças e os jovens para inserção profissional na sociedade como cidadãos qualificados. Conforme documentos publicados pelo Ministério do Trabalho e da Solidariedade Social (TEM, 2001), tanto o Peeti quanto o PIEF possuem parcerias com empresas, destinadas ao emprego de maiores de 16 anos. Nesses casos, o aluno fica na empresa $60 \%$ de seu tempo e $40 \%$ no PIEF, até que obtenha a certificação do $9^{\circ}$ ano escolar. Portanto, 
4 Escalão social é uma escala que classifica as famílias conforme o rendimento. Há escalão A, B, C, D, conforme a faixa salarial familiar. Para ter direito ao recebimento do escalão social, a família necessita estar em uma situação legalizada na escola, ou seja, boa parte dos imigrantes residentes em Portugal não usufrui do escalão social e assim necessitam pagar o valor inteiro da alimentação escolar.

5 Consultar: <www.ibge.gov.br>. o programa atua na perspectiva da qualificação e inserção profissional, tentando fazer com que os adolescentes encontrem um emprego qualificado no futuro, reproduzindo as mesmas tendências liberais individualistas já relatadas anteriormente.

Além dessas ações, desde 2008, Portugal implementou a escola em tempo integral, com crianças do Ensino Básico (nove primeiros anos de escolarização, seis a 14 anos). As crianças e adolescentes frequentam as disciplinas curriculares obrigatórias em um período e, em outro, desenvolvem atividades de enriquecimento curricular (inglês, artes, música, esportes). O almoço e os lanches são fornecidos por uma empresa terceirizada. As famílias com menor rendimento recebem subsídios para alimentação e material escolar, conforme o escalão social ${ }^{4}$ de pertencimento. Não obstante o fato de as crianças permanecerem o dia todo na escola, a exploração do trabalho infantil persiste, como veremos a seguir.

\section{A PERSISTÊNCIA DO PROBLEMA DA EXPLORAÇÃO DO TRABALHO INFANTIL REVELADA PELOS DADOS ESTATÍSTICOS NO BRASIL E EM PORTUGAL}

Como decorrência de denúncias e de pressões internacionais favoráveis à implementação de políticas de combate ao trabalho infantil, tanto o governo brasileiro quanto o português desenvolveram formas de quantificação e caracterização desse trabalho. No Brasil, a coleta de dados é feita pelo IBGE - Pesquisa Nacional por Amostra de Domicílio (PNAD) que, conforme informações do site ${ }^{5}$, considera quatro categorias de trabalho infantil:

1) Ocupação remunerada em dinheiro e em benefícios (moradia, alimentação, roupas) na produção de bens e serviços.

2) Ocupação remunerada em dinheiro ou benefícios.

3) Ocupação sem remuneração na produção de bens e serviços, desenvolvida pelo menos uma hora na semana (ajuda domiciliar, doméstica ou agrícola).

4) Ocupação desenvolvida pelo menos uma hora na semana em atividades agrícolas e produtoras de bens e na construção de edifícios e outras benfeitorias.

Segundo o IBGE (2006), 5,1 milhões de crianças e adolescentes trabalham no Brasil, correspondendo a 11,5\% da população na faixa etária correspondente. Das crianças e adolescentes ocupados, 41,4\% estão em trabalhos agrícolas, proporção que chega a 62,6\%, entre cinco a 13 anos e que diminui conforme aumenta a faixa etária. Em quase todas as regiões, o percentual de ocupados em atividades agrícolas na faixa etária de cinco a 13 anos é superior ao daqueles envolvidos em atividades não agrícolas, à exceção da Região Sudeste.

Por esse quadro, podemos observar que, na faixa etária entre 5 e 13 anos, há predomínio de trabalho não 
remunerado (57\%), seguido do trabalho para o próprio consumo (21\%), do trabalho doméstico $(15,1 \%)$ e de trabalhadores por conta própria (6,8\%). Já entre 14 e 15 anos, predominam trabalhadores não remunerados (41,5\%), empregados e trabalhadores domésticos $(41,3 \%)$, trabalhadores para o próprio consumo (10\%) e trabalhadores por conta própria (7\%). Conforme a idade avança, percebemos que aumenta o número de trabalhadores domésticos e diminui o número de não remunerados e voltados para o próprio consumo.

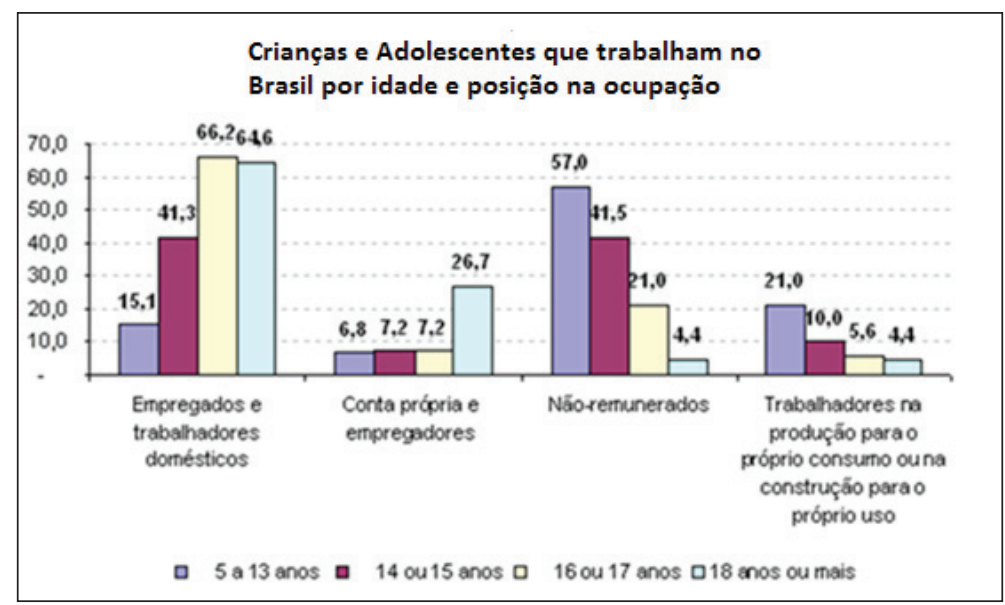

Gráfico 1 - Crianças e adolescentes que trabalham no Brasil por idade e posição na ocupação Fonte: IBGE (2006)

Conforme dados do IBGE (2006), 49,4\% das crianças e adolescentes entre cinco e 17 anos de idade no Brasil exercem afazeres domésticos. Essa atividade é destinada com maior frequência e intensidade às meninas, acentuando como a divisão sexual do trabalho e as questões de gênero se iniciam desde a tenra idade. Na faixa etária de cinco a 17 anos, pouco mais de um terço $(36,5 \%)$ dos homens cuidam dos afazeres domésticos, enquanto a proporção é de $62,6 \%$, para as mulheres - situação que se repete em todas as faixas etárias.

A frequência à escola ou à creche cresce de acordo com o aumento do rendimento mensal domiciliar. Enquanto, para as crianças e os adolescentes de zero a 17 anos de idade residentes em domicílios com rendimento mensal domiciliar per capita na faixa de sem rendimento até menos de $1 / 4$ de salário mínimo a taxa de frequência à escola ou creche é de $69,3 \%$, para aquelas moradoras em domicílios com rendimento per capita de dois ou mais salários mínimos, a taxa atinge 86,0\%. A partir desses dados, percebemos que o acesso à escola e a opção pelo trabalho infantil não dependem do nível cultural e de escolaridade familiar; mas, sobretudo, das condições materiais da família da qual a criança faz parte. 


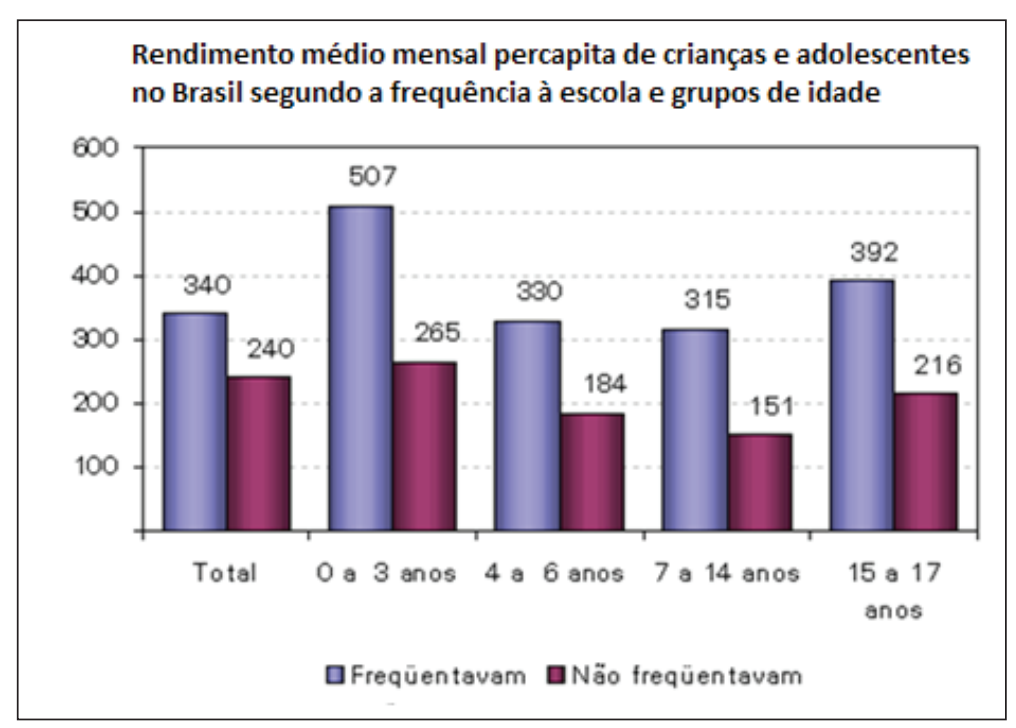

Gráfico 2 - Rendimento médio mensal percapita de crianças e adolescentes no Brasil segundo a frequência à escola e grupos de idade Fonte: IBGE (2006).

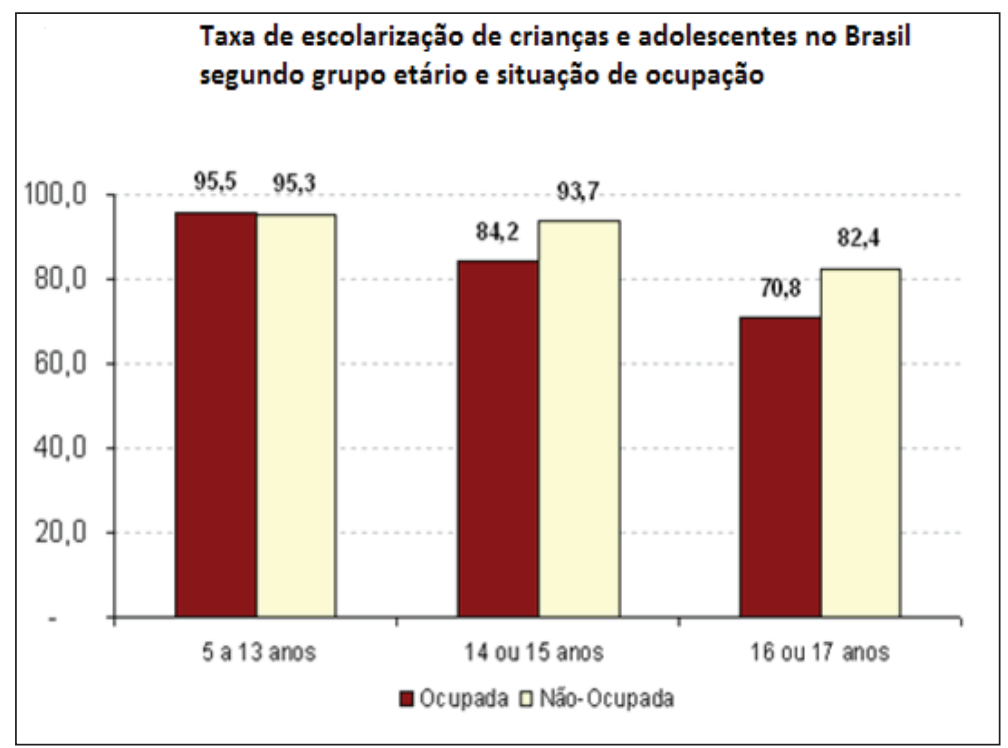

Gráfico 3 - Taxa de escolarização de crianças e adolescentes no Brasil, segundo grupo estário e situação na ocupação Fonte: IBGE (2006).

Como podemos observar, frequentar a escola não é suficiente para não trabalhar, uma vez que, embora existam grandes contingentes de crianças que trabalham e deixam de estudar, a maior parte das crianças que trabalham frequentam a escola: 95,5\% ( 5 a 13 anos); 84,2\% (14 ou 15 anos); 70,8\% (16 ou 17 anos). Também é possível observar que, com o avançar da idade, a taxa de escolarização diminui, e o número de crianças que trabalham aumenta.

No caso de Portugal, foi criado o Sistema de Informação e Estatística do Trabalho infantil (SIET), que realiza investigações por meio da aplicação de questionários que definem o trabalho de crianças como sinônimo de atividade 
6 Eles decorrem da tipologia (forma de classificação de objetos utilizada primeiramente pela medicina), que classifica a partir de semelhancas e diferenças em relação ao outro objeto. $\mathrm{O}$ funcionalismo aplicou a tipologia nas Ciências Sociais, esquecendo a relação dialética entre os objetos presentes na realidade. econômica, integrando desde atividades cotidianas relacionadas à organização da vida (como arrumar a própria cama, lavar o prato após as refeições, organizar os brinquedos etc.) até situações de exploração do trabalho (como costurar bolas para multinacionais em sistema de cotas realizado em domicílio), prejudiciais ao desenvolvimento físico, cognitivo e social (SIET, 2004).

A diferenciação entre atividades cotidianas e exploração infantil, não considerada pelo sistema português, constitui elemento essencial para a compreensão das formas contraditórias que o trabalho assume com o desenvolvimento da sociedade capitalista. Essa distinção tem por pressuposto histórico o fato de que nem sempre o trabalho foi explorado e produtor de mais-valia. A exploração nasceu com a sociedade capitalista.

Conforme Marx (2006), a ausência dessa diferenciação entre trabalho geral e trabalho capitalista tende a naturalizar a exploração da mais-valia:

Mas, logo se vê que é um método muito cômodo demonstrar a eternidade do modo capitalista de produção ou para fazer do capital um elemento material imorredouro da produção humana. O trabalho é uma condição eterna da existência humana. O processo de trabalho não é mais do que o próprio trabalho, considerado no momento da sua atividade criadora. Os elementos gerais do processo de trabalho, por conseguinte, são independentes de todo e qualquer desenvolvimento social determinado. Os meios e os materiais de trabalho, uma parte dos quais é produto de trabalhos precedentes, desempenham seu papel em qualquer processo de trabalho, em qualquer época e em todas as circunstâncias. (MARX, 2006, p. 64-65).

$\mathrm{Na}$ atualidade, a forma capitalista de produção tem se tornado hegemônica e submetido toda e qualquer forma de trabalho à produção ou à realização direta ou indireta de mais-valia, compondo o trabalho abstrato coletivo. Exemplos podem ser observados nos casos das crianças que trabalham junto da família costurando sapatos ou daquelas que trabalham na agricultura familiar. Trata-se de trabalho infantil realizado no núcleo familiar, mas articulado à produção da mais-valia por meio do sistema de cotas ou de empresas integradas.

De acordo com as orientações da OIT, o trabalho infantil em Portugal pode ser caracterizado em três tipos ${ }^{6}$ :

1) Atividade econômica: conceito amplo que inclui atividades exercidas por menores de 16 anos, remuneradas ou não, desenvolvidas pelo menos uma hora por semana.

2) Trabalho infantil: conceito limitado que exclui crianças economicamente ativas e maiores de 12 anos, que trabalham menos de 15 horas por semana em trabalhos leves e regulares. 
3) Trabalho perigoso: todas as atividades que, por sua natureza, têm efeitos nocivos à criança. Compreende todos os menores de 18 anos em atividades perigosas ou desenvolvidas em locais perigosos, quer por implicarem excesso de carga, quer por péssimas condições de trabalho, intensidade de horas e periculosidade.

Como podemos perceber, as definições portuguesas para a caracterização do trabalho infantil não incluem a categoria "exploração" e dividem o trabalho infantil em perigoso (semelhante às piores formas de trabalho infantil definidas pela OIT) e trabalhos leves. Na exclusão da categoria "exploração", encontra-se a diferença entre o trabalho geral e o trabalho produtor de mais-valia. As crianças sempre contribuíram para a organização da vida familiar, mas nem sempre foram exploradas. Foi com o advento do sistema capitalista de produção que nasceu a exploração da mais-valia, através da qual o trabalhador recebe um salário cujo valor é inferior ao número de horas trabalhadas. Ao ignorar essa relação, classificando o trabalho nas três tipologias explicitadas anteriormente (a, b, c), o SIET contribui ao ocultamento da exploração e à ausência de crítica ao trabalho assalariado na relação capitalista de produção. A mesma crítica poderíamos aplicar às definições de trabalho infantil pelo IBGE no Brasil.

Tabela 3 - Crianças e adolescentes que exercem atividade econômica, segundo os diferentes tipos de trabalho em Portugal

\begin{tabular}{lcccc}
\hline Grupos etários & $\begin{array}{c}\text { Trabalho não } \\
\text { pefigoso } \\
\text { (até 15 horas) }\end{array}$ & $\begin{array}{c}\text { Trabalho não } \\
\text { perigoso } \\
\text { regular } \\
\text { (de 15 a 35 horas) }\end{array}$ & $\begin{array}{c}\text { Trabalho perigoso } \\
\text { (local e tarefas perigosas } \\
\text { e > 35 horas semanais) }\end{array}$ & $\begin{array}{c}\text { Atividade } \\
\text { econômica } \\
\text { (total) }\end{array}$ \\
\hline De 6 a 11 anos & 9.768 & 2.265 & 2.401 & 14.434 \\
De 12 a 14 anos & 13.439 & 2.187 & 5.502 & 21.182 \\
15 anos & 4.576 & 2.617 & 6.105 & 13.298 \\
Total & 2.837 & 7.069 & 14.008 & 48.914 \\
\hline
\end{tabular}

Fonte: SIET (2004).

Os dados do SIET, conforme explicita a Tabela 3, ilustram que, entre as 1.190 .658 crianças abrangidas pelo estudo, 48.914 (4,1\%) exercem alguma atividade econômica. Entre as que exercem atividades econômicas, 34.906 (71\%) encontram-se em situação de trabalho infantil considerado leve e regular, e 14.008 (28\% dos que desenvolvem alguma atividade econômica) exercem tarefas perigosas. Assim, o trabalho infantil considerado leve e o trabalho infantil não perigoso são classificados como atividades econômicas. Dessa forma, o exercício de atividade econômica por crianças e adolescentes aparece como algo normal que não concorre com o tempo que as crianças e os adolescentes têm para estudar, brincar, fazer arte, música, ciência e, enfim, para se apropriarem do saber historicamente acumulado. Como podemos perceber, o problema detectado pela classificação do sistema português tende a questionar apenas o trabalho infantil que degenera precocemente o trabalhador 
7 Os gráficos do SIET denominam crianças e adolescentes trabalhadores como menores. Embora não concordemos com essa terminologia, optamos por mantê-la. Para Chauí (1990), palavra menor se refere a alguém da classe trabalhadora que é o infrator, o delinquente, o abandonado. "Menor" é um termo pejorativo. Pode parecer que este caráter negativo, pejorativo da palavra "menor" advenha de um sentido recente. Kant enumera, de acordo com o pensamento liberal, quem são os "menores" na sociedade, isto é, aqueles que não têm direito ao uso público da razão "os trabalhadores, as mulheres, os velhos e as crianças" (2009, p. 1). e, assim, ameaça a reprodução do sistema capitalista. Outra atividade produtora de mais-valia pode concorrer com o tempo da escola e da infância, desde que não ameace a vida do trabalhador e, portanto, consiga garantir sua perpetuação como força de trabalho.

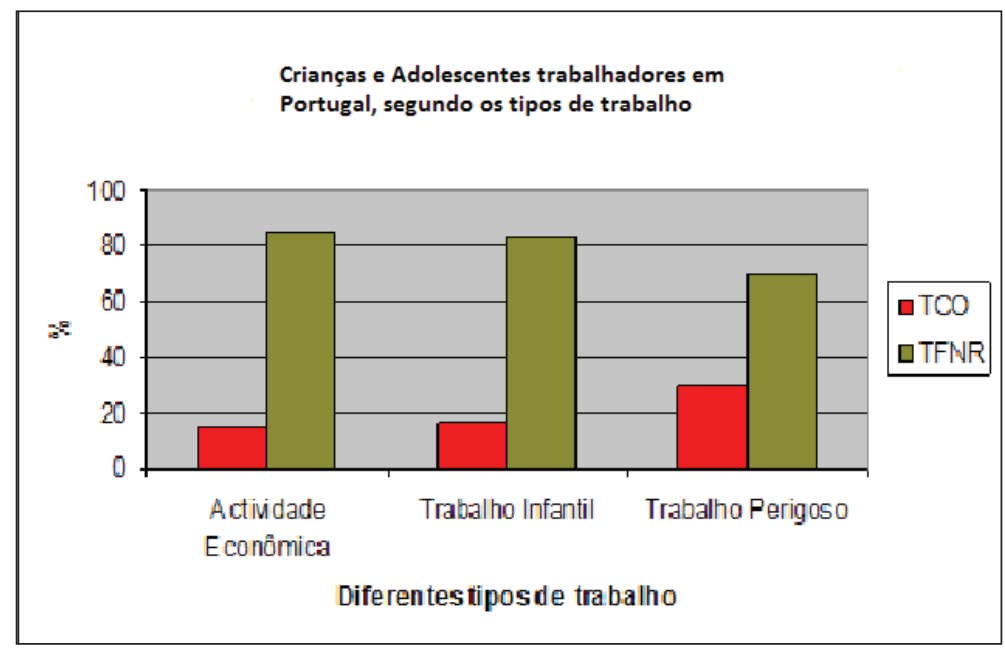

Gráfico 4 - Crianças e adolescentes trabalhadores em Portugal, segundo os tipos de trabalho Fonte: SIET (2004).

Já no Gráfico 4, observamos que, entre as crianças ${ }^{7}$ que trabalham ou que, conforme a denominação portuguesa, realizam algum tipo de atividade econômica, $85,3 \%$ relacionam-se ao trabalho familiar não remunerado, e 14,7\%, ao trabalho realizado por conta de outrem. Nas situações de trabalho infantil, percebemos que $83,1 \%$ são realizadas no núcleo familiar, e $16,9 \%$, em outras situações. Com relação ao trabalho perigoso, 70,4\% são desenvolvidos em contextos familiares, e 29,6\% mantêm-se por conta de outrem. A maior incidência de trabalho infantil em contextos familiares tende a tornar o problema invisível. Fato esse acentuado com a proibição do trabalho de crianças pela legislação portuguesa (o que também se revela no Brasil), estimulando a contribuição à sobrevivência familiar em espaços invisíveis, domésticos, privados e de difícil fiscalização.

Na pesquisa realizada pelo SIET, foi possível constatar que os meses de julho, agosto e setembro (período de férias escolares em Portugal) apresentam o maior índice de trabalhos realizados por crianças e adolescentes, com $82 \%, 85,1 \%$ e $63,8 \%$ respectivamente. No Brasil, embora o sistema de coleta do IBGE não tenha considerado a maior ou menor incidência de trabalho infantil durante o período de aulas e de férias escolares, nossas pesquisas sobre o trabalho infantil na fumicultura evidenciam que o período das férias escolares de verão (dezembro, janeiro e meados de fevereiro) coincide com a época de colheita do fumo (época de trabalho mais intenso na fumicultura, pois as famílias, além de colherem o fumo, precisam secar as folhas na estufa, enrolar a manilha e fazer os fardos), e as crianças trabalham, no âmbito familiar, nesse período. 


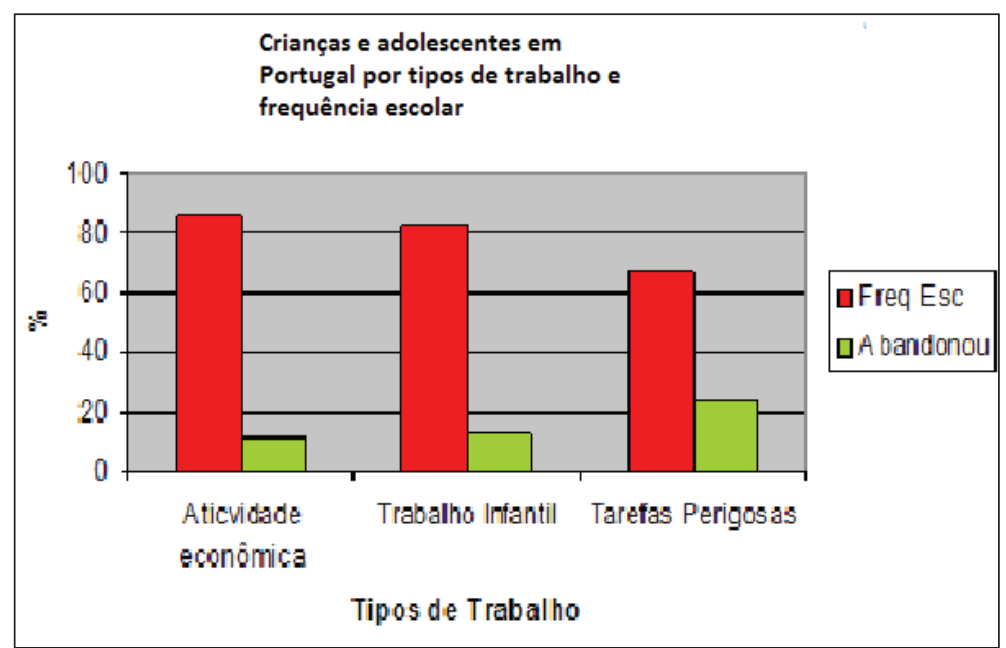

Gráfico 5 - Crianças e adolescentes em Portugal por tipos de trabalho e frequência escolar Fonte: SIET (2004).

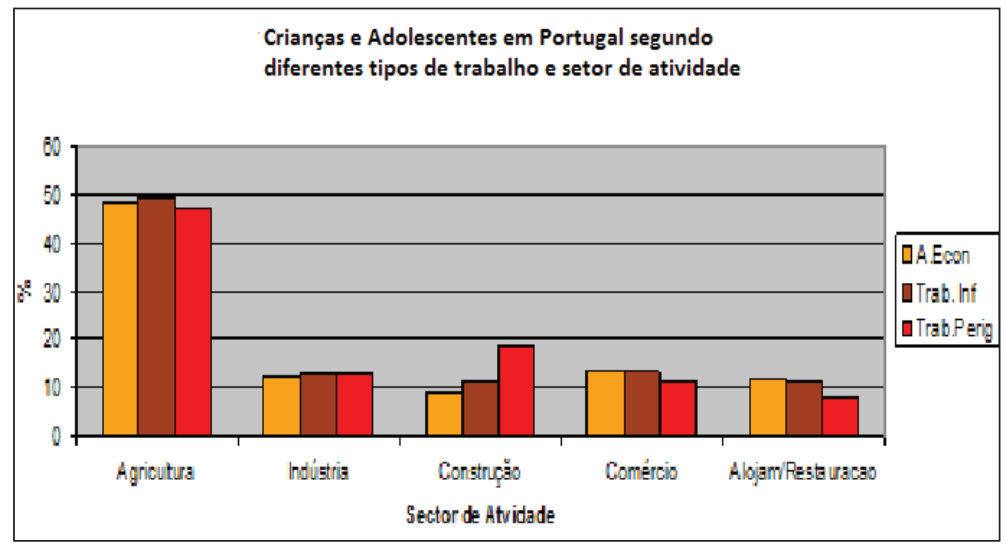

Gráfico 6 - Crianças e adolescentes em Portugal segundo diferentes tipos de trabalho e setor de atividade Fonte: SIET (2004).

O setor com maior incidência de trabalho infantil em Portugal é a agricultura, reunindo 48,4\% de atividade econômica (termo utilizado para atividades exercidas por menores de 16 anos, remuneradas ou não, desenvolvidas pelo menos uma hora por semana); 49,2\% das situações de trabalho infantil (termo utilizado para atividades realizadas por menores de 12 anos que trabalham até 15 horas por semana em trabalhos leves e regulares); e 47,1\% dos menores que exercem atividades perigosas (termo empregado para menores de 18 anos que exercem atividades em locais perigosos com excesso de carga, péssimas condições de trabalho, intensidade de horas e periculosidade). Já na construção civil, observamos a absorção da menor taxa do que o SIET intitula trabalho infantil, mas significativo índice $(18,6 \%)$ do que o SIET intitula trabalho perigoso. O mesmo é notado na indústria, que absorve $8,9 \%$ das atividades econômicas e $18,6 \%$ das atividades perigosas. Já nos setores de comércio, alojamento e restauração, observamos o 
contrário, sendo maior o índice de atividade econômica e menor o de trabalho perigoso.

\section{CONSIDERAÇÕES FINAIS}

Os dados portugueses sobre o trabalho infantil esclarecem que as crianças que trabalham em Portugal não deixam de frequentar a escola (85\%). Embora as políticas portuguesas instituam a escola durante período integral (matutino e vespertino) e concedam benefícios com subsídios, bolsas e descontos para os escalões sociais mais baixos, elas não conseguem coibir a necessidade da contribuição da criança no orçamento familiar. Portanto, as políticas e os programas que propõem a resolução do trabalho infantil pela escolarização (PIEF e Peeti) são insuficientes, pois as crianças que frequentam a escola não deixam de trabalhar.

No Brasil, a coleta de dados do trabalho infantil é realizada pelos auditores fiscais do Ministério do Trabalho (por meio da fiscalização de denúncias) e pelo IBGE por meio da PNAD. Como o trabalho, pela legislação brasileira, é permitido a partir dos 16 anos, na condição de aprendiz, somente são computados dados de trabalho infantil relativos às piores formas, pois são trabalhos proibidos até 18 anos de idade. Ao não considerarem o trabalho na condição de aprendiz como explorado, os dados acabam por ocultar a relação de produção de mais-valor a qual mostra que os aprendizes estão, muitas vezes, dentro das empresas executando tarefas que, à priori, deveriam ser executadas por outro adulto contratado. Nessa condição, o adolescente aprende a ser trabalhador produtivo; assim, perpetua sua condição de produtor de mais-valia. As políticas internacionais direcionam suas ações às piores formas de trabalho infantil, ou seja, às mais degenerativas de exploração precoce, que, por sua vez, ameaçam a reprodução da relação capitalista, e não a eliminação de todo trabalho infantil explorado.

Foi possível observarmos que a legislação proíbe o trabalho de crianças, a escola torna-se obrigatória, e as políticas de transferência de renda tentam resolver o problema ignorando suas origens estruturais. O reformismo ignora as contradições estruturais do sistema e tenta corrigir de forma paliativa o que é irreformável. Não obstante, a exploração do trabalho infantil persiste no Brasil e em Portugal, como atestam os dados do SIET e do IBGE.

$\mathrm{O}$ acesso à escolarização e ao conhecimento historicamente acumulado é um direito de todos os seres humanos e pode ser utilizado para instrumentalizar a classe trabalhadora tanto para a luta contra a forma opressora do capitalismo quanto para seu desenvolvimento social, cognitivo, emocional, físico. Entretanto, isso é diferente de considerar a escola capaz de solucionar os problemas cuja origem está entranhada nas contraditórias relações que submetem o trabalho ao capital nessa sociedade. É nessa relação dialética que a escola se localiza. Ela é, ao mesmo 
tempo, um meio capaz de instrumentalizar o trabalhador contra sua opressão e desenvolvê-lo individualmente, porém insuficiente para erradicar a exploração.

\section{REFERÊNCIAS}

AGUIAR, A. de. Programa de Erradicação do Trabalho Infantil/PETI de Florianópolis - percepção dos adolescentes egressos. Trabalho de conclusão de Curso (Serviço Social) - Universidade Federal de Santa Catarina, Florianópolis, 2004. (115p.).

BRASIL. Lei ${ }^{\circ}$ 9.394, de 20 de dezembro de 1996. Estabelece as Diretrizes e Bases da Educação Nacional. Diário Oficial da República Federativa do Brasil, Brasília, DF, 23 dez. 1996. Disponível em: <http://www.mec.gov. br/ legis/pdf/ LDB.pdf>. Acesso em: 3 abr. 2009.

BRASIL. Lei no 8.069, de 13 de julho de 1999. Dispõe sobre o Estatuto da Criança e do Adolescente e dá outras providências. Diário Oficial da República Federativa do Brasil, Brasília, DF, 13 jul. 1999a. Disponível em: <http:// www.planalto.gov.br/ccivil_03/leis/L8069.htm>. Acesso em: 4 abr. 2009.

BRASIL. Senado Federal. Decreto legislativo 178. Aprova os textos $\left({ }^{*}\right)$ da Convenção 182 e da Recomendação 190 da Organização Internacional do Trabalho (OIT) sobre a proibição das piores Formas de Trabalho Infantil e Ação Imediata para sua Eliminação. Diário Oficial da República Federativa do Brasil, Brasília, DF, 4 dez. 1999b. Disponível em: <http://legis.senado.gov.br/legislacao/ListaPublicacoes.action?id=228425> . Acesso em: 3 abr. 2009.

BRASIL. Decreto $\mathrm{n}^{\mathrm{O}}$ 4.134, de 15 de fevereiro de 2002. Promulga a Convenção no 138 e a Recomendação no 146 da Organização Internacional do Trabalho (OIT) sobre Idade Mínima de Admissão ao Emprego. Diário Oficial da República Federativa do Brasil, Brasília, DF, 18 fev. 2002. Disponível em: <http://www.planalto.gov.br/ ccivil_03/decreto/2002/d4134.htm>. Acesso em: 4 abr. 2009.

BRASIL. Decreto 7.083, de 27 de janeiro de 2010. Dispõe sobre o Programa Mais Educação. Brasília, 2010. Diário Oficial da República Federativa do Brasil, Brasília, DF, 27 jan. 2010. Disponível em: <http://www.planalto. gov.br/ccivil_03/_at02007-2010/2010/decreto/d7083. htm>. Acesso em: 4 abr. 2009.

CHAUÍ, Marilena. Criança. In: AUED, B.; VENDRAMINI, C. (orgs.) A persistência do trabalho infantil na indústria e na agricultura (Santa Catarina no contexto brasileiro). Florianópolis, SC: Insular, 2009. 
CUNHA, Luiz Antônio Constant Rodrigues da. Educação e desenvolvimento social no Brasil. Rio de Janeiro: Francisco Alves, 1991.

DAVIS, Mike. Planeta favela. São Paulo: Boitempo, 2006.

DECLARAÇÃO DE BARCELONA. Carta das cidades educadoras (Primeiro Congresso Internacional das Cidades Educadoras). Barcelona, 1994. Disponível em http:// comunidadesdeaprendizagem.org.br/Cartadascidadeseducadoras.pdf.

FERNANDES, Florestan. Educação e sociedade no Brasil. São Paulo: Dôminus, 1966.

FERRARO, Alceu Ravanello. Liberalismo e educação ou por que o Brasil não podia ir além de Mandeville. Revista Brasileira de Educação, Rio de Janeiro, v. 14, n. 41, maio/ago. 2009.

GOULART, Maria Antônia. A intersetorialidade da educação integral. In: BRASIL. TV Escola. Salto para o futuro. Boletim XVIII, Brasília, ano 13, ago. 2008. p. 17-19.

INSTITUTO BRASILEIRO DE GEOGRAFIA E ESTATÍSTICA. Pesquisa Nacional por Amostra de Domicílio 2006. Brasília, DF. 2006. Disponível em: <www.ibge.gov. br>. Acesso em: 2 abr. 2009.

INSTITUTO BRASILEIRO DE GEOGRAFIA E ESTATÍSTICA. Trabalho infantil - Tema Especial - Panorama Recente. Pesquisa Nacional por Amostra de Domicílios/2007. Diretoria de Pesquisas, Coordenação de Trabalho e Rendimento, 2008.

INSTITUTO BRASILEIRO DE GEOGRAFIA E ESTATÍSTICA. Pesquisa Nacional por Amostra de Domicílio 2009. Brasília, DF. 2009. Disponível em: <www.ibge.gov. br>. Acesso em: 4 abr. 2009.

INSTITUTO NACIONAL DE ESTUDOS E PESQUISAS EDUCACIONAIS ANÍSIO TEIXEIRA. 2009. Disponível em: <http://observatorio.inep.gov.br>. Acesso em: 3 abr. 2009.

KASSOUF, Ana Lúcia; FERRO, Andrea Rodrigues. Avaliação dos impactos dos Programas de Bolsa-Escola sobre o trabalho infantil no Brasil. 2004. Programa de Pós-Graduação em Economia, Universidade de São Paulo, Piracicaba. Disponível em: http://www.cepea.esalq. usp.br/br/documentos/texto/avaliacao-do-impacto-dos-programas-de-bolsa-escola-sobre-o-trabalho-infantil-no-brasil.aspx 
KLEIN, Lígia. Regina. Trabalho alienado $\mathbf{x}$ trabalho como princípio educativo: contradição não resolvida no trato do trabalho infanto-juvenil. In: CONGRESSO PAULISTA DE EDUCAÇÃO MÉDICA, São Paulo, 2010. Anais do Congresso Paulista de Educação Médica. São Paulo, 2010. s/p?

MARICATO, Ermínia. Posfácio. In: DAVIS, Mike. Planeta favela. São Paulo: Boitempo, 2006. p. 209-224.

MARX, Karl. O capital: crítica da economia política. Livro 1. Vol I. São Paulo: Nova Cultural, 1988a.

MENEZES, G. G. de C. A luta pela erradicação do trabalho infantil em Santa Catarina. 2002. 118 páginas. Dissertação (Mestrado em Sociologia Política) - Programa de Pós-Graduação em Sociologia Política, Universidade Federal de Santa Catarina, Florianópolis, 2002.

MÉSZÁROS, István. Para além do capital. São Paulo: Boitempo, 2001.

MÉSZÁROS, István. A educação para além do capital. São Paulo: Boitempo, 2005.

MOLL, Jaqueline. Conceitos e pressupostos: o que queremos dizer quando falamos de educação integral. In: BRASIL. TV Escola. Salto para o futuro. Boletim XVIII, Brasília, ano 13, ago. 2008. p. 11-16.

ORGANIZAÇÃO INTERNACIONAL DO TRABALHO. Estatísticas do trabalho infantil (manual de metodologia para recolha de dados). Genebra, mar. 2004. Disponível em: <http://www.ilo.org/public/portugue/region/ampro/ brasilia >. Acesso em: 6 jun. 2005.

OLIVEIRA, Francisco de. Crítica à razão dualista. $O$ Ornitorrinco. São Paulo: Boitempo, 2003.

ORGANIZAÇÃO DAS NAÇÕES UNIDAS. Disponível em: <http://www.onu.org.br>. Acesso em: 23 mar. 2011.

ORGANIZAÇÃO DOS ESTADOS IBERO-AMERICANOS PARA A EDUCAÇÃO, A CIÊNCIA E A CULTURA (OEI). Relatório de Gestão 20o8. Brasília, DF, 2008.

ORGANIZAÇÃO INTERNACIONAL DO TRABALHO. Estatísticas do trabalho infantil (manual de metodologia para recolha de dados). Genebra, mar. 2004. Disponível em: <http://www.ilo.org/public/portugue/region/ampro/ brasilia>. Acesso em: 6 jun. 2005.

PILOTTI, Francisco; RIZZINI, Irene. A arte de governar crianças. Rio de Janeiro: Instituto Interamericano del Niño; Editora Universitária Santa Úrsula; Anais, 1995. 
PINCELLI, Ângela Cristina Santos. Trabalho infanto-juvenil na fumicultura e responsabilidade social empresarial: o discurso da Souza Cruz. 2005. 112 f. Dissertação (Mestrado em Sociologia Política) - Programa de Pós-Graduação em Sociologia Política, Universidade Federal de Santa Catarina, Florianópolis, 2005.

SISTEMA DE INFORMAÇÃO ESTATÍSTICA SOBRE O TRABALHO INFANTIL. Inserção precoce no mercado de trabalho. Ministério da Segurança Social e do Trabalho: Lisboa, 2004.

SISTEMA DE INFORMAÇÃO ESTATÍSTICA SOBRE O TRABALHO INFANTIL. Tipificação das situações do trabalho dos menores: nota complementar à publicação de 2004. Ministério da Segurança Social e do Trabalho: Lisboa, 2008.

SILVER, Beverly J. Forças do trabalho: movimentos de trabalhadores e globalização desde 1870. São Paulo: Boitempo, 2005.

SMITH, A. Inquérito sobre a natureza e as causas das riquezas das nações. Vol. 1. 2. ed. Lisboa: Fundação Calouste Gulbenkian, 1989.

FUNDO DAS NAÇÕES UNIDAS PARA A INFÂNCIA. Tendências para a Educação integral. São Paulo: Fundação Itaú Social, 2011.

Recebido em: 31/03/2017 Aprovado em: 10/07/2017 